\title{
AVÓS E NETOS: O EXERCÍCIO DE UMA PARENTALIDADE
}

\author{
Ana Luiza Xavier Scremin \\ Centro Universitário Franciscano - UNIFRA - Brasil \\ Cristiane Bottoli \\ Centro Universitário Franciscano - UNIFRA - Brasil
}

\section{Resumo}

Este trabalho apresenta a parentalidade em uma forma peculiar e cada vez mais recorrente, os avós que assumem a criação dos netos. Para compreender como a parentalidade é assumida ou exercida pelos avós na atualidade, investigando como ocorre esta configuração, quais os papéis desempenhados pelos avós na criação dos netos, e semelhanças e diferenças da atual criação com a de seus filhos. Foram entrevistados três casais de avós que criam pelo menos um dos seus netos, sem a presença dos pais, e após os dados foram analisados através da análise de conteúdo. Concluiu-se assim que o motivo o qual levou os netos a morarem com os avós, o tempo em que estão nesta convivência e a relação que esses avós mantinham anteriormente com seus filhos que contribuiu para a intimidade com os netos, foi o que mais interferiu no exercício da parentalidade dos avós entrevistados.

Palavras-Chave: Avós; Netos; Parentalidade.

\section{Introdução:}

Ao longo dos anos, as famílias tinham definições e modelos pré estabelecidos de seus membros, normalmente pai, mãe e filhos, e das funções que exerciam neste núcleo familiar (CRUZ E UZIEL, 2014).A família atual não se apresenta em sua configuração como as famílias de antigamente. Essa modificação nas configurações familiares é resultado, principalmente, das transformações sociais, como por exemplo, a maior longevidade, o menor número de filhos e a maior expectativa de vida, que provocaram alterações na estrutura e dinâmica familiar, entre elas o convívio de várias gerações e até a realidade de morarem em um mesmo ambiente, compartilhando as tarefas da casa e os cuidados da família (MEIRELES E TEIXEIRA, 2014).

Quando isso acontece, não é raro encontrar avós que são responsáveis pela educação dos netos enquanto os pais trabalham, e em alguns casos, são incumbidos de responsabilidades parentais frente aos netos, assumindo forma integral os cuidados para com eles, perdendo um pouco essa visão de avós de açúcar, muito presentes na cultura familiar brasileira (LIMA E JUNIOR, 2014). Realidade esta, que remete à necessidade de estudar essas relações, já que 
envolve dois momentos do desenvolvimento de certa forma distantes e diferentes, bem como, as implicações desta forma de configurar a parentalidade, fato este que está cada vez mais frequente. Por causa desse convívio entre gerações tão diferentes e distantes, é de extrema importância o estudo dessas relações e seus impactos na família atual e no exercício da parentalidade.

O conceito de parentalidade, cada vez mais utilizado, refere-se aos cuidados parentais e as relações entre pais e filhos, sendo citado principalmente em estudos sobre famílias na atualidade. Analisando os estudos sobre a história das famílias e das relações familiares, percebe-se que o termo parentalidade é recente, e que nem sempre esteve presente, pois é resultado de uma evolução, assim como as relações familiares e as funções parentais, que foram construídas ao longo da história, de acordo com as transformações da sociedade (GORIN et al, 2015).

A parentalidade caracteriza-se por um conjunto de tarefas realizadas pelas figuras parentais, com a intenção de promover o desenvolvimento integral da criança e do adolescente, sendo assim, é algo construído por cada pessoa desde sua infância, baseado nos exemplos de parentalidade e das histórias transgeracionais, e não necessariamente deverão ser exercidas apenas pelo pai e mãe biológicos. Pois, vão além das questões do dia a dia, modificando-se e acompanhando cada fase do desenvolvimento, tendo extrema importância no desenvolvimento e estruturação psíquica do bebê e na formação da personalidade da pessoa.

Neste estudo, o enfoque foram os avós que criam seus netos, sem a presença dos pais, pois além deste ser um fenômeno cada vez mais frequente nas famílias atuais, existem poucos estudos sobre este tema. Desta forma, esta pesquisa objetivou compreender como a parentalidade é assumida ou exercida pelos avós na atualidade, quando os pais não residem no mesmo endereço. Para isto, foram investigados os papéis que os avós desempenham na criação dos netos, analisando como se configura a parentalidade entre avós e netos, identificando as semelhanças e diferenças na criação dos seus filhos, buscando verificar se é possível que os avós ocupem os lugares de pai e de mãe na vida desses netos, e como isso é percebido.

\section{Parentalidade:}

A família atual tem sofrido diversas modificações, não sendo, em alguns casos, formada apenas por um pai, uma mãe e filhos, modelo este que predominava antigamente. 
Porém, não só a configuração familiar foi modificada, mas também os papéis materno e paterno, assim como as formas de exercer a parentalidade. A família continua sendo uma estrutura organizadora e segura, um espaço fundamental para trocas afetivas e transmissão simbólica (ROUDINESCO, 2003). Embora essas referências tenham uma nova configuração, ambas são necessárias para a maturação e a construção do psiquismo da criança, além disso, a parentalidade não precisa ser exercida necessariamente em uma relação de consanguinidade, ela pode ser apenas de aliança, sendo produto de uma transmissão intergeracional, referência de afeto e reconhecimento para a criança (PASSOS, 2007).

Assim, tornar-se pai e tornar-se mãe depende principalmente da história de cada um dos pais, indo além do modelo familiar tradicional (ZORNING, 2010). A criança também contribui neste processo de parentalização dos pais, e ela faz isso demonstrando, por exemplo à mãe, o prazer que sente quando está em seu colo ou sendo cuidada. No início, a criança ainda não entende a representação das figuras materna e paterna, mas vai aos poucos reconhecendo estes lugares em virtude dos cuidados materno e paterno e, aos poucos, distingue as funções exercidas por cada um (LEBOVICI, 2004).

As funções materna e paterna são fundamentais para a estruturação e desenvolvimento da criança, sendo estas de ordem prática e peculiares em cada fase. Estas funções modificamse neste processo, gerando alterações e exigindo dos pais que acompanhem essas alterações e modifiquem-se também (BORGES, 2005).

A autora supracitada, em pesquisa realizada, com a intenção de mapear, observar e considerar as vivências do exercício das funções materna e paterna, a partir da visão de quatro casais com filhos entre zero e cinco anos, concluiu que a função paterna não se refere apenas a ser pai biológico, mas também ser capaz de sustentar "física e emocionalmente os filhos". No mesmo estudo, percebeu também que as funções começavam ainda na gravidez, na maneira como o pai tratava a mãe, e a maneira que eles vivenciavam esse momento era determinante na vida emocional da criança (BORGES, 2005).

Desta forma, a parentalidade conforme Houzel (2004) divide-se entre três eixos: "O exercício da parentalidade", que situa cada pessoa aos laços e que a partir disto tem direitos e deveres; "A experiência da parentalidade", que é a experiência de tornar-se pai, de ter o desejo pela criança e assumir os papéis parentais; e "A prática da parentalidade", que são as tarefas básicas de cuidados do dia a dia a quais são exercidas com e para a criança.

A partir disso, entende-se que o processo da parentalidade com a transmissão das histórias de vida dos cuidadores e das suas relações com os seus pais, que vão dando forma às representações de ser pai e ser mãe, e que neste momento, conforme Darchis apud Passos 
(2000) há uma volta à família de origem para ressignificar suas relações e assim instaurar a parentalidade, reorganizando suas identidades no que diz respeito à conjugalidade e aos aspectos transgeracionais.

Desta forma, quando ocorre uma impossibilidade da presença dos pais, o exercício da função materna e paterna, muitas vezes, é transferido ou solicitado aos avós, que são vistos como família extensa e têm a preferência dos pais, antes da babá e da escola. Em alguns casos, os avós passam a exercer uma influência mais direta na conduta dos pais e seus filhos (BORGES, 2005). Sendo assim, além de, nesta relação, entre netos e avós, haver um maior espaço para confidências, cumplicidade e aprendizado das histórias familiares, onde pode existir maior liberdade do que no relacionamento com os pais, poderá ocorrer em virtude da realidade que se apresenta conforme Cardoso (2010), a participação mais direta dos avós na rotina, além de responsabilizarem-se por aspectos financeiros, bem como, levar e buscar na escola, até a transmissão de valores e crenças, num exercício de parentalidade.

\section{Avós na contemporaneidade e a criação dos netos:}

A imagem dos avós como frágeis, velhos, dependentes e passivos está em transformação, pois, atualmente, a idade deles pode ser comparada a de seus pais, porém estes envelheciam antes e necessitavam dos cuidados de seus sucessores, tanto nas questões pessoais como nas decisões familiares e financeiras. Atualmente se vislumbram situações em que os avós acabam por ser responsáveis pela manutenção familiar, e muitas famílias dependem das suas aposentadorias como fonte de renda (SOUZA, 2009).

Tornar-se avô e avó é um evento significativo do ciclo vital que diante das mudanças demográficas e sociais vem tomando outras formas (CARDOSO, 2010). A visão dos avós como responsáveis pela família e pela educação dos netos é um fenômeno recente, o qual proporciona que várias gerações morem e convivam em um mesmo ambiente. Este convívio intergeracional pode ser estimulado, visando a um benefício mútuo, com a troca de afetos, de conhecimento e comunicação entre as gerações (SILVA, 2012).

O passado dos avós é referência para os netos, pois contam com emoção o que passou em sua época e revivem este momento colaborando para o enriquecimento da identidade do neto. Por sua vez, este reintegra elementos importantes, como a tradição, a maneira de falar e o modo de interpretar a realidade. Isto contribui para a relação avós e netos e faz com que um compreenda melhor o outro (CASTELLON, 2004). 
Esta transmissão de valores é que dá sentido à relação avós e netos, faz com que os avós sintam-se "continuados", e é esta continuidade transgeracional que gera uma fantasia de imortalidade, um sentido de coerência em sua vida e para os netos uma forma de desenvolvimento de identidade, buscando nas vivências, recordações, imagens dos avós, competências para construir novas relações (GOMES-PEDRO, 2006).

Assim como os pais, os avós também desempenham um papel educativo junto aos netos, porém, muitas vezes, a dificuldade está em obedecer duas normas contraditórias, a não interferência na educação dada pelos filhos aos netos e a necessidade de ajudá-los nesta tarefa (SOUZA 2006). Desta forma, quando os avós vivem na mesma casa que os netos, é natural que hajam responsabilidades diretamente ligadas aos cuidados e educação dos mesmos (GOMES, 2006). Contudo, não se pode pensar que esse processo não cause desconforto nas pessoas envolvidas, pois, em algumas situações, os avós têm sentimentos ambivalentes em relação aos cuidados dos netos, enquanto os pais estão fora de casa, sentindo-se, muitas vezes, sobrecarregados com a tarefa de levar os netos às suas diversas atividades (AMAZONAS E BRAGA, 2006).

Quando esta situação acontece, às vezes inesperadamente, essa população mais velha ocupa um outro lugar na sociedade, o de "cuidador dos netos", reunindo características maternas e paternas nessa relação (ALVES, 2013). Ademais, quando os avós assumem totalmente a criação dos netos poderá haver conflitos quanto a sua postura como avó/avô e/ou mãe/pai, pois, assim como querem cumprir o papel culturalmente atribuído de avós, têm a necessidade de agir como pais. Dependendo da idade e fase do desenvolvimento de ambos, essa tarefa torna-se difícil, visto que não têm a mesma disposição de quando eram mais novos, mas também possuem mais tempo para se dedicar, de forma integral, aos cuidados com os netos. Em alguns casos durante a criação dos mesmos, os avós podem ressignificar suas experiências enquanto pais e tentar acertar coisas que antes julgaram errar (SILVA et al, 2010).

Dentre os diversos motivos que levam os avós a sairem do lugar idealizado, de avós que mimam para se tornarem responsáveis por exercer essa parentalidade estão, a ausência desses pais por óbito, negligência nos cuidados, ou até mesmo imaturidade, que às vezes pode levar esses avós a uma obrigação moral ou uma tentativa de reparação, onde tentam ser para os seus netos, o que não foram para os seus filhos (LIMA E JUNIOR, 2014). Estudos trazem que esses avós ao substituir os pais nos cuidados dos netos, independente dos diversos motivos que impedem que os pais exerçam suas funções, assumiram essa responsabilidade 
por na maioria dos casos já participarem, eventualmente, dos cuidados dos netos (MAINETTI E WANDERBROOCKE, 2013).

Diante desta realidade apresentada, entende-se a necessidade de pensar como esses avós compreendem o seu lugar junto aos netos, no momento em que eles assumem diretamente o cuidado destes na ausência dos pais, e como se percebem diante da constituição desta parentalidade.

\section{Metodologia:}

A pesquisa realizada foi de cunho qualitativo, sendo útil quando aplicada em situação onde as variáveis são relevantes, onde o pesquisador lida com ações e fatos relacionados ao comportamento humano.

Participaram da pesquisa 3 (três) casais de avós, que criam os netos, sem a presença dos pais na mesma residência. Nenhum dos três casais possui um trabalho fixo, todos estão aposentados. Quanto à guarda desses netos, os avós 1 possuem a guarda definitiva, no caso dos avós 2 a guarda é da mãe e dos avós 3 o responsável legal é o pai. A amostra foi por acessibilidade e por conveniência. Os participantes estão identificados na tabela a seguir:

\begin{tabular}{|l|c|c|l|}
\hline Avós & Idade & $\begin{array}{c}\text { Tempo que residem com } \\
\text { os netos }\end{array}$ & \multicolumn{1}{|c|}{$\begin{array}{c}\text { Idade do(s) netos(s) que } \\
\text { residem junto }\end{array}$} \\
\hline Avó 1 & 67 & 17 anos & 21 anos \\
Avô 1 & 85 & 1 ano & 13 anos \\
\hline Avó 2 & 63 & 63 & 14 anos \\
Avô 2 & 59 & 8 anos & \\
\hline Avó 3 & 60 & & \\
Avô 3 & & &
\end{tabular}

Foram realizadas entrevistas semiestruturadas, conforme roteiro pré-estabelecido, separadamente com cada avó e avô. O primeiro contato com os avós foi realizado por telefone a fim de explicar os objetivos da pesquisa e para agendar a data e local para um encontro. As entrevistas foram realizadas, de forma oral e gravadas separadamente com cada avô e avó, sem tempo pré-determinado, visando a uma melhor fidedignidade das informações trazidas pelos participantes. Em seguida, o material gravado foi transcrito para que fosse possível 
interpretar os resultados por meio da análise de conteúdo. Esta transcrição será guardada pelo período de cinco anos e caso os participantes desejarem, os resultados da pesquisa serão apresentados aos mesmos. ${ }^{1}$

A análise ocorreu a partir das falas dos participantes à luz da teoria revisada, sendo elencadas categorias de discussão.

\section{Análise e Discussão dos Resultados:}

A análise foi realizada a partir de três categorias: a constituição da parentalidade; os papeis desempenhados pelos avós na criação dos netos, afinal, qual o lugar que os avós ocupam na vida dos netos. Essas categorias foram preestabelecidas de acordo com os objetivos.

\section{A constituição da parentalidade:}

Nesta categoria será discutido como se constituiu a parentalidade dos avós e quais fatores que os levaram a assumir a criação dos netos. Nos três casos ela ocorreu de forma diferente e muito particular.

Com relação aos Avós 1, o neto já convivia com eles durante o dia e à noite voltava para a casa dos pais e foi morar definitivamente com os avós quando a mãe faleceu, vindo o pai falecer logo em seguida. Nesta época o neto tinha quatro anos, e os avós têm a guarda dele desde então. Atualmente o neto tem vinte e um anos.

Já os Avós 2, receberam o filho e a nora em casa quando ela engravidou, pois os dois eram muito jovens. Na época do nascimento do neto, o casal ainda morava na casa dos pais dele, e quando mudaram de residência levaram o neto, que ficou com eles até se separarem. Após este fato ele foi morar com a mãe, até os treze anos idade que judicialmente poderia escolher com quem morar e, então, pediu para morar com os avós paternos, o que já faz um ano que ele está definitivamente na casa deles.

No caso dos Avós 3, os pais nunca viveram juntos, sendo que a neta morou primeiro com os avós maternos e sua mãe. Mais tarde, com seis anos de idade e em época escolar, veio morar com os avós paternos, período este em que o pai da neta ainda morava com eles.

\footnotetext{
${ }^{1}$ Foi entregue o Termo de Consentimento Livre e Esclarecido que foi assinado pelos avós participantes, garantindo os direitos de sigilo e de decisão de participar ou não da pesquisa, além de assegurar o anonimato dos participantes através de nomes fictícios, respeitando sempre os procedimentos éticos para a realização da Pesquisa em Psicologia com Seres Humanos, presentes na Resolução $N^{\circ}$ 016/2000, do Conselho Federal de Psicologia (CFP) e do conselho Nacional de Saúde, Resolução No 466/2012. O projeto foi aprovado pelo Comitê de Ética do Centro Universitário Franciscano sob o parecer número 33773014.1.0000.5306
} 
Durante um ano quis e foi morar com a mãe novamente, mas preferiu voltar a morar com os avós paternos. Hoje nem a mãe nem o pai residem na mesma cidade que a filha, a qual atualmente tem 14 anos e há 8 anos mora com os avós paternos.

Muitas vezes, os avós assumem a responsabilidade pelos netos e o papel de pais diante de uma situação considerada dramática, que pode ser o rompimento do casal, choque no modelo familiar, morte de um ou de ambos os pais, envolvimento com drogas, gravidez na adolescência, dentre outras situações, que fazem desses avós figuras relevantes na socialização e criação dos netos, como pode ser observado na descrição dos casos acima (BARROS, 1987; MOREIRA, 2013).

Em situações que envolvem separação dos pais, por ser, geralmente, uma situação desestabilizadora para toda a família, os avós são considerados uma importante fonte de apoio às crianças e ao próprio casal na resolução dos seus problemas, sendo figuras de apoio instrumental, fornecendo cuidados diários, ajuda financeira e também prestando apoio emocional (LEITE, 2001; DIAS, 2002). Em alguns casos eles assumem integralmente os cuidados dos netos, assim como no caso dos Avós 2 e 3.

Assim, assumindo o papel de cuidadores dos netos, eles desempenham uma forma de parentalidade, que é definida como a capacidade psicológica de exercer esta função, ou seja, ter a competência de "ser pai ou mãe suficientemente bons para seus filhos" (MORALES, 2004, p. 195), e neste caso, para os netos, pois essa capacidade independe de os filhos serem biológicos. Isto acontece, porque a parentalidade é algo construído, indo além de um fator biológico, como resultado de uma transmissão intergeracional que é herdada dos próprios pais (LEBOVICI, 2004).

Além disso, os três casais salientaram que sempre conviveram com os netos e que os assumiram por uma necessidade, pela falta física e pela pouca idade dos pais. Os Avós 1 referiram a morte dos pais como principal responsável pela mudança do neto para sua casa:

Porque ele é meu neto, além de ser meu neto, foi criado com a gente porque ele não tem pai, (...) então eu assumi tudo, quer dizer que tudo que se refere a ele é comigo (AVÔ 1).

A Avó 1 conta que ele já era muito apegado a ela, mesmo antes da morte dos pais, como exemplifica na fala:

Na verdade ele sempre morou, eu ficava com ele de dia e de noite levava pra casa da mãe e do pai [...] daí no fim eu perdi minha filha [...] daí eu fiquei com o neto, ele já era bem dizer meu (AVÓ 1). 
A Avó 2 quando soube da gravidez da namorada do filho, levou a nora para morar com eles, tendo assim participado da gravidez e infância do neto, como afirma na fala:

$\mathrm{Na}$ verdade ele nasceu na nossa casa, [...] ele foi o primeiro neto da família, foi uma benção, uma criança muito amada, [...] a gente assumiu, cuidava, quando ele era bebezinho [...] praticamente dormia no meio nosso, ele tinha o quarto dele mas ele ia dormir conosco (AVÓ 2).

O Avô 2 também relata a presença constante na vida do neto:

Nós acolhemos ela (nora) em casa, acolhemos o neto quando nasceu. [...] a gente sempre esteve na vida dele, pra mim foi bom, ser avô bem cedo, com 49 anos (AVÔ 2).

Os Avós 3 (avós paternos) recebiam a neta nas férias quando ela ainda morava com os avós maternos, o pai ainda morava em casa, como contam os avós.

Apesar de morar com a mãe dela e os avós maternos, ela sempre vinha pra cá, passava um mês, ela sempre tinha contato com a gente (AVÔ 3).

Ela vinha muito seguido pra cá e ficava uns quantos dias e ela era bem apegada ao pai dela também, que na época morava conosco (AVÓ 3).

Nesta categoria pode-se perceber que o vínculo entre avós e netos já existia antes mesmo de residirem juntos. A partir disto, é possível observar os efeitos positivos dessa relação, pois quanto mais contato com esse avô e avó mais forte é a ligação entre os dois, o que pode facilitar esse processo com relação ao momento em que os avós assumem o cuidado integral dos netos (OLIVEIRA, 2010). Desta maneira, considera-se que este afeto existente por parte dos avós é uma construção a partir da convivência na família, da relação com seus filhos e do acompanhamento da gestação desses netos (LEITE, 2004). Durante a infância, a relação entre eles ocorre por intermédio dos pais, que precisam levar os netos à casa dos avós para que ambos estabeleçam uma boa relação (DIAS \& SILVA, 2001), e isto foi percebido durante as falas dos avós entrevistados.

Desta forma, entende-se que os três casais assumiram os netos a partir de uma necessidade oriunda de uma situação de impossibilidade da presença dos pais, advinda de morte, separação ou imaturidade, sendo que o vínculo existente ente os avós e os netos antes mesmo de residirem juntos, foi um fator determinante para a boa adaptação deles com a nova situação familiar. Esta realidade leva a questionar se caso os avós não tivessem contato com os netos antes da separação dos pais, eles aceitariam assumir este lugar, e essa relação seria benéfica para ambos. Além disso, outro fato que pode ter contribuído para esta realidade, parece estar associado à relação dos pais da criança com os avós cuidadores, pois durante a infância os pais são importantes para o surgimento dessa relação avós e netos. 


\section{Os papeis desempenhados pelos avós na criação dos netos:}

Nesta segunda categoria, através dos relatos, foram identificados os papéis que os avós desempenharam e desempenham na vida dos netos. Com relação a este aspecto os avós contribuíram relatando o seu dia a dia, as responsabilidades que têm frente à educação dos netos, do relacionamento com os pais do neto e se dividem ou não as tarefas relacionadas aos mesmos. Nos três casos, apareceram os avós como cuidadores em tempo integral. Os Avós 1 e 3 definem-se como responsáveis por tudo o que diz respeito aos netos; quanto aos Avós 2, estes dividem algumas responsabilidades referentes ao neto com os pais, pois estes moram perto da casa dos avós.

Pela perda da filha e do genro, os Avós 1 assumiram todos os cuidados sem ter nenhuma interferência de terceiros, pois são os únicos cuidadores do neto, como mostram as falas abaixo.

\footnotetext{
A gente criou ele como filho né, [...] todas regalias que eu posso dar pro neto eu dou, (...) é a missão que eu tenho (AVÔ 1).

Eu trabalhava em casa por telefone, [...] mas levava no colégio, no futebol, taekwondo, tudo o que ele quis fazer (AVÓ 1).
}

No caso dos Avós 2, os pais ainda são presentes, então ele não foi criado exclusivamente pelos avós, mesmo que sejam responsáveis dentro de sua casa, no cotidiano, os pais ainda têm algumas obrigações, como exemplo a financeira, de acordo com o que relata o Avô 2:

\footnotetext{
Na verdade não tem pitaco nem da mãe nem do pai, só do vô e da vó, porque os dois não moram junto, eu é que resido diariamente com ele, pra pegar, levar no colégio [...], e na financeira a gente não tem obrigação, mais são os pais que têm que arcar com os estudos, roupa, mas se bem que a gente termina dando também as coisas que são necessárias, mas por livre espontânea vontade (AVÔ 2).
}

Eles também acham que os pais do neto se acomodaram com esta situação, pois eles (os avós) fazem o papel paterno e materno que lhes é atribuído socialmente, então acreditam que os pais pensam que não precisam fazer esse papel.

Eu acho que isso aí é comodismo deles (pais), porque como a gente atende tudo, até a educação eu sempre me dediquei mais sabe, me preocupei,cobrava mais (AVÓ 2).

Neste caso, fica evidente que o fato dos avós se disponibilizarem a cuidar dos netos mais ativamente, pode tirar a responsabilidade dos pais e fazer com que eles não assumam ou assumam parcialmente os papéis parentais (MAINETT et al, 2013). 
Com os Avós 3, mesmo que o filho e a nora ainda sejam presentes, e o pai seja o responsável legal, a neta sempre recorre aos avós quando precisa de algo, sendo estes os responsáveis pelos cuidados diários com ela.

Legalmente o pai dela tem a guarda [...] mas ela passa o tempo todo com a gente, então é a gente que deixa ela ir ou não deixa [...], sou eu que levo no médico, que cuido os remédios, que tem que acordar de noite pra ver se tá com febre, se tá bem, quando chove eu levo no colégio (AVÓ 3).

Segundo Cardoso (2010), mesmo que os avós não tenham a guarda formalizada judicialmente, ainda são de grande importância na formação dos netos, porque participam da sua rotina, indo dos cuidados cotidianos, como pegar e levar na escola, aos financeiros, até a transmissão dos valores e crenças.

Além disso, os avós também se tornam cuidadores voluntários quando os pais trabalham o dia inteiro, ou nos casos de morte ou divórcio, e, mesmo que sintam que não tiveram escolha, como no caso dos Avós 1, ambos buscam aproveitar o tempo disponível exercendo as funções que são necessárias (OLIVEIRA, 2007).

Estas funções são de âmbito físico e simbólico, que vão além do papel que cabe ao pai e a mãe, sendo desempenhadas por adultos tutelares, neste caso os avós. Portanto implica em "adultos que desejam a criança e que são contingentes de determinados atributos que os tornam capazes de exercer cuidados físicos e psíquicos” (BORGES, 2005, p.26).

Ademais, foi questionado se eles percebiam alguma semelhança da criação dos seus filhos com o neto que reside junto a eles. Durante as entrevistas os avós contaram as dificuldades da época em que só tinham os filhos, o que mudou ou continuou igual na sua forma de agir quando desempenhavam o papel de educador de ambos, os três avós tentam agir como agiram com os filhos, mas citam alguns aspectos que facilitaram ou dificultaram no processo de educação dos netos.

Os avós 1 trazem o atual momento da sociedade como um desafio, mas tentam dar a mesma educação dada aos filhos.

Crio como filho, é meu filho, eu que educo ele, [...] quanto mais vai seguindo a vida, a gente tem que ter mais cuidado [...] devia ser mais exigente, é difícil criar um jovem hoje em dia [...] a juventude é mais difícil (AVÔ 1).

A avó 1 também traz a maturidade como um elemento importante no atual momento de vida em que criou o neto:

Foi muito bom eu criar ele, porque eu tava mais madura, tinha até mais paciência com ele (AVÓ 1). 
A avó 2 fala sobre a aposentadoria, que proporcionou mais tempo com os netos do que com os filhos.

Aposentado tem mais tempo, eu vejo assim, que a gente sendo avó aposentado principalmente, tem mais tempo disponível pra olhar, pra conversar, pra sair, como a gente faz com ele (AVÓ 2).

Outro fator destacado por Oliveira (2007), diz respeito ao fato de que os avós sendo saudáveis e tendo mais disposição e tempo para exercer o cuidado dos netos, tornam-se cuidadores com mais facilidade. Além disso, há uma melhor socialização e utilização deste tempo livre da aposentadoria, inclusive possibilidade de voltar a fazer planos (MOREIRA, 2013).

Além dos aspectos positivos dessa relação de parentalidade dos netos, ocorre também algumas dificuldades, como exemplo o fato de sentirem-se cansados a perda da liberdade de sair, viajar por causa da rotina diária da neta e o compromisso com a escola, assim como relata a avó 3:

\footnotetext{
A gente procura agir com ela como agia com os filhos né, mas às vezes é mais difícil um pouco, tem uma diferença, meu filho mais novo tem 28 anos, ela tem 14, então às vezes a gente tá cansado um pouco, procura sempre dar atenção, acompanha as coisas do colégio (...) é um tempo que poderia ser pra gente, e a gente já se prende um pouco por ela, mas é válido (AVÓ 3).
}

Há diversos sentimentos envolvidos quando os avós cuidam diretamente dos netos, podem apresentar confusão de papel por estarem desempenhando uma função que, na realidade, seria dos pais, inclusive alguns sentimentos ambivalentes como o cansaço e medo de perder sua privacidade como também o de realização, renovação, orgulho e satisfação de terem contribuído com seus filhos e netos (ARAUJO et al, 2010).

Neste caso, isto ocorreu de maneira diferente em cada casal, pode ser atribuído ao tipo de relação desta forma de parentalidade, ao fato de sentirem-se mais pais ou avós de seus netos e de quererem ou não assumir este lugar que estão ocupando no momento. A etapa da vida desses avós associada à idade dos netos quando foram morar juntos, assim como a presença ou ausência dos pais também influenciou os tipos de cuidados que esses netos precisavam receber, assim determinando a intensidade dessa relação.

\section{Afinal, qual o lugar que os netos ocupam na vida dos avós?}

No caso dos Avós 1, eles têm dificuldades de diferenciar o papel de avós e de pais. A idade que o neto foi morar na casa deles e a circunstância que isto aconteceu, a morte dos dois pais, foram determinantes neste caso, além de a guarda ser destes avós, o que legaliza esta 
relação, fato este que também colabora para que eles se permitam estar neste lugar de pai e mãe, pois o neto não tem outra referência.

Eu tinha a guarda, era mãe e vó [...] sou as duas coisas, não sei desvincular, sou avó e mãe (AVÓ 1).

Ao contrário, os avós 2 não se nomeiam pais, apenas desempenham este papel, sendo responsáveis pelos cuidados diários. Isto ocorre pelo fato de os pais morarem perto, dividirem algumas responsabilidades e pelo pouco tempo em que moram com este neto, apenas um ano.

Faço às vezes papel de pai, às vezes avô, mas mais avô, [...] não tem aquela obrigação [....] matriarcal e patriarcal de anos, que o pai e a mãe tem que dar o sustento pro filho (AVÔ 2).

Eu faço papel de avó, [...] eu vejo que tenho tempo mais disponível e eu faço isso com amor e prazer, [...] ali é casa de avó mesmo (AVÓ 2).

Na sociedade atual, os avôs e avós tendem a ser figuras privilegiadas no imaginário das pessoas. São, na maioria das vezes, amados e recordados com carinho. Por este motivo talvez os avós 2 sintam mais prazer em ser avós do que pais, além disto, como o neto foi criado grande parte da vida pelos pais, pode ser que se o envolvimento dos avós interferir na educação que o filho e a nora deram ao neto que gere algum conflito com os mesmos, e percam esta imagem tão idealizada de avós (LOPES et al, 2005; PIRES, 2010).

Já os avós 3 parece que não se permitem ocupar este lugar de pai e de mãe, o casal assume que faz o papel parental e que não são avós convencionais, mas não querem estar no lugar de pai e de mãe, apenas desempenham este papel, pois com os pais ausentes no dia a dia da neta, alguém tem que assumir essa responsabilidade.

\footnotetext{
No dia a dia a gente faz papel de pai, porque a gente tem que decidir o que ela precisa, cobrar o que a gente entende que tem que fazer, faz papel de pai porque tem que ter alguém, [...] querer bem significa estabelecer limites (AVÔ 3).

$\mathrm{Na}$ ]verdade a gente tá com o papel trocado, tem que exigir coisas como pai e mãe, mas na verdade não é [...] tem que dar limites, não pode deixar muito na vontade dela, não pode muito fazer o papel de vó e de vô (AVÓ 3).
}

Barros (1987) traz a responsabilidade pela transmissão de conhecimentos, valores, afeto e autoridade dentro da família e a participação na vida dos netos como papel de avós. Porém, sem a mesma responsabilidade e obrigação de educar, que é considerado o papel primordial dos pais. Fato este que foi percebido tanto na fala dos avós 3 como dos avós 2, citados anteriormente.

De acordo com Souza (2006) há alguns tipos diferentes de avós, os formais, que procuram comportarem-se como eles pensam ser o papel de avós, mantendo a diferença em 
relação ao papel parental, como visto nos avós 2, e os avós que têm estilo "substitutivo parental”, que são os que assumem todas as responsabilidades relacionadas aos netos, como os avós 1 e avós 3.

Assim, entende-se que, conforme os avós entrevistados, existem diferentes tipos de avós; os que assumem as responsabilidades, como se fossem os próprios pais dos netos, o que se torna mais fácil quando os pais dos mesmos estão ausentes, adotando um estilo parental. Já, os avós que mesmo morando juntos com o neto, conseguem ser "apenas" avós, assim chamados avós formais. E por último, os avós que gostariam de ser somente avós, mas pela necessidade precisam agir de uma forma mais autoritária, igualando-se à função socialmente atribuída aos pais.

\section{Considerações finais:}

A família atual, ainda que predominantemente seja formada por pais e filhos tem tomado outras formas, acrescentando neste núcleo familiar, alguns membros, como tios, primos, avós. Estes, algumas vezes, por determinada situação tornam-se responsáveis pela educação de seus netos. Além disso, hoje os avós não são mais idosos incapacitados e dependentes, pois, alguns deles ainda trabalham, tem uma vida socialmente ativa, e por esses motivos têm mais oportunidades de conviver com seus netos, podendo fazer parte da vida deles por um período mais longo do que há um tempo atrás.

Através das entrevistas realizadas com os três casais de avós que moram com seus netos, sem a presença dos pais, concluiu-se que alguns fatores foram fundamentais para a constituição destas parentalidades. Dentre eles, o fato motivador desta configuração, que foi, a morte da filha e do genro, no caso dos avós 1; a separação dos pais do neto, no caso dos avós 2; a imaturidade do casal, na época adolescentes, para criar a filha, transferindo este papel aos avós 3. Assim, as causas que conduziram os netos a morarem com os avós parecem ser fator determinante para o estabelecimento da relação até o presente momento e o lugar que os mesmos ocupam no exercício desta parentalidade.

Além disso, a relação que os pais tiveram com seus filhos, foi determinante para que houvesse um contato com os netos antes mesmo de irem morar com os avós, pois a partir da boa relação que existia anteriormente entre pais e filhos tinham, proporcionando um bom convívio familiar, fortaleceu e facilitou o vínculo entre avós e netos. Nos três casos entrevistados, havia uma convivência com esses avós antes de residirem juntos, passando o dia com eles enquanto os pais trabalhavam, morando perto ou convivendo alguns meses nas 
férias, criando assim um laço forte entre eles e uma relação benéfica para ambos, que teve continuidade quando foram residir juntos, o que consequentemente também influenciou na forma de constituírem-se enquanto pai e mãe neste exercício.

A pesquisa também mostrou que embora o papel dos avós seja essencial na vida desses netos, pois são eles que cuidam, acompanham as atividades diárias e se responsabilizam-se pelos mesmos, principalmente nos dois casos onde os pais existem, ainda parece que o fator biológico é o determinante para o significado de ser pai e de ser mãe. Sendo mais fácil nomearem-se como avó e avô, mesmo que haja o desejo de também serem pai e mãe, o que nestas realidades pesquisadas se faz muito presente este significado, do que apenas o fato de estarem sendo avô e avó.

Igualmente chama a atenção o fato de que nas entrevistas realizadas os três casais foram muito receptivos, ainda que as entrevistas tenham sido efetuadas separadamente, os casais tiveram comportamentos e direcionamentos semelhantes nas suas falas. No caso dos avós 1, os dois estavam bem dispostos a falar deste assunto, mesmo que ainda sofram com a perda da filha, eles já estão bem adaptados com esta configuração, pois há muito tempo criam o neto.

Os avós 2 mesmo morando há pouco tempo com o neto, assumem o lugar de avós, pois é assim que se definem, também não tiveram nenhuma dificuldade em falar sobre o assunto. Já os avós 3, mesmo que morem com a neta há muito tempo, confundem-se entre pais e avós, por esse motivo, relataram pouco sobre sua história, em muitos momentos não sabiam o que falar, muito preocupados com o direcionamento da pesquisa, precisando ser questionados em alguns momentos, ainda assim contando elementos íntimos e relevantes para a pesquisa em questão. Pode ser que isto tenha acontecido por não ter um papel definido dentro da vida desta neta em virtude da realidade familiar.

O estudo foi muito relevante, pois é uma temática ainda pouco explorada, apesar de ser uma realidade vivida por muitas famílias atualmente. Desta forma, seria interessante que houvesse mais estudos envolvendo avós e netos, inclusive com relação à percepção que estes netos têm dessa relação, ou até mesmo a visão destes pais, quando possível, em ver os avós ocupando o lugar de cuidadores dos seus filhos. Entender estas novas formas de parentalidade faz com que os profissionais tenham outro olhar sobre este assunto, visto que podem se deparar a qualquer momento com essas novas configurações.

Este estudo oportunizou que esses avós repensassem esta convivência, este lugar que ocupam na vida dos netos, fazendo-os reviver fatos, elaborar situações mais difíceis, conduzindo-os a outras experiências, fazendo-os aprender a lidar com esta dupla tarefa de ora 
ser avó e avô e em outros momentos serem também pai e mãe, redefinindo a cada dia seu lugar na vida dos netos.

\title{
GRANDPARENTS AND GRANDCHILDREN: THE EXERCISE OF PARENTING
}

\begin{abstract}
This paper presents the parenting in a peculiar and even more frequently way, the grandparents that assume the upbringing of their grandchildren. To understand how this parenting occurs it was investigated how parenting is assumed or exercised by grandparents today, investigatin, some similarities and differences of the current upbringing with their children's, also searching if these grandparents have the role of father and mother in their grandchildren's life. It was interviewed three couples of grandparents that raise at least one of their grandchildren, without the presence of their parents, and then the data were analyzed by the analyses of content. It was concluded the reason why the grandchildren were raised by their grandparents, the time they are in this companionship and the relationship that these grandparents had with their children that contributed to their intimacy with their grandchildren, these were what most interfere in the practice of the interviewed grandparents' parenting.
\end{abstract}

Keywords: Grandparents; Grandchildren; Parenting.

\section{ABUELOS Y NIETOS: EL EJERCICIO DE LA PARENTALIDAD}

\section{Resumen}

Este trabajo presenta la parentalidad en una forma peculiar y cada vez más recurrente, los abuelos que asumen la creación de los nietos. . Para comprender cómo la parentalidad es asumida o ejercida por los abuelos en la actualidad, investigando cómo ocurre esta configuración, y cuales los papeles desempeñados por los abuelos en la creación de los nietos, algunas semejanzas y distorciones de la actual creación con la de sus hijos, buscando verificar también si estos abuelos ocupan los lugares de padres y de madres en la vida de los nietos. Fueron entrevistados tres parejas de abuelos que crean por lo menos uno de sus nietos, sin la presencia de los padres, y luego los datos fueron analizados a través de análisis de contenido. Concluyese así que el motivo al cual llevo los nietos a vivieren con los abuelos, el tiempo en que están en esta convivencia y la relación que esos abuelos mantuvieron anteriormente con sus hijos que contribuyó para la intimidad con los nietos, fue lo que más interfirió en el ejercicio de la parentalidad de los abuelos entrevistados.

Palabras clave: Abuelos; Nietos; Parentaliedad

\section{Referências}

ALVES, Sâmea Moreira Mesquita. Cuidar ou ser responsável? Uma análise sobre a intergeracionalidade na relação avós e netos. Dissertação de mestrado da Universidade Estadual do Ceará. Ceará, 2013. 
AMAZONAS, Maria Cristina Lopes de Almeida; BRAGA, Maria da Graça Reis. Reflexões acerca das novas formas de parentalidade e suas possíveis vicissitudes culturais e subjetivas. Ágora, Rio de Janeiro. v. IX n. 2 jul/dez 2006 177-191.

ARAÚJO, Cristina Pinheiro de; DIAS, Cristina Maria de Souza Brito. Avós Guardiões de Baixa Renda. Pesquisas e Práticas Psicossociais, 4 (2), São João Del-Rei, jul. 2010.

ARAUJO, Mayeve Rochane Gerônimo Leite. O impacto do divorcio parental sobre os filhos, papel dos avós neste processo. Revista interlocuções, ano 1, n 1, jan./jun. 2001, pág. 11-27.

BORGES, Maria Luiza Soares Ferreira. Função materna e função paterna, suas vivências na atualidade. Dissertação de Mestrado. Uberlândia: Universidade Federal de Uberlândia, 2005.

CAMPOS, Claudinei José Gomes. Método de análise de conteúdo: ferramenta para a análise de dados qualitativos no campo da saúde. Revista Brasileira de Enfermagem, Brasília, v. 57, n. 5, p. 611-614, set./out., 2004.

CARDOSO, Vanessa Silva. Os avós e a concessão de guarda judicial de netos na perspectiva do ciclo de vida familiar. Tese de Doutorado da Universidade de Brasília, 2010.

CASTELLON, Armando Barriguete. Figuras da parentalidade: o pai, o avô. A psicodinâmica do avô. In: SOLIS-PONTON, Letícia (Org.). Ser pai, ser mãe parentalidade: um desafio para o terceiro milênio. Casa do psicólogo. São Paulo, 2004. Pág. 155-160.

CRUZ, Antonia Maria Alves de La; UZIEL ,Anna Paula. Transformações sociais e culturais da família: considerações iniciais a partir de um caso. Conexões Psi., v.2, n.1, p. 57-83, jan./jun., 2004.

DIAS, Cristina Maria de Souza Brito. A influencia dos avós nas dimensões familiar e social. Revista Symposium, ${ }^{\circ}$ 1/ 2, ano 6, jan./dez. 2002, p. 34-38.

GIL, Antonio C. Métodos e técnicas de pesquisa social. São Paulo: Atlas, 2006.

GOMES- PEDRO. João. O papel dos avós no século XXI. In: João Muñoz de Oliveira (Coord.). Povos e Culturas. Editora: CEPCEP, 2006. Pág. 11-23.

GORIN, Michelle Christof; MELLO, Renata; MACHADO, Rebeca Nonato; FÉRESCARNEIRO, Terezinha. O estatuto contemporâneo da parentalidade. Revista SPAGESP, Ribeirão Preto, v. 16, n. 2, p. 3-15, 2015.

HOUZEL, Didier. As implicações da parentalidade. In: SOLIS- PONTON, Letícia (Org.). Ser pai, ser mãe parentalidade: um desafio para o terceiro milênio. São Paulo: Casa do Psicólogo, 2004, p. 47-52.

LIMA, César Augusto Saouda de; JUNIOR , Armando Rocha. O processo de reparação na mudança da avosidade para a parentalidade baseado na custódia e educação dos netos. Revista Educação, São Paulo, v.9, n.1, pág.61-83, 2014. 
LOPES, Ewellyne Suely de Lima; NERI, Anita Liberalesso; PARK, Margareth Brandini. Ser avós ou ser pais: os papéis dos avós na sociedade contemporânea. Textos Envelhecimento, Rio de Janeiro, v. 8, n. 2, 2005.

MAINETTI, Ana Carolina; WANDERBROOCKE, Ana Claudia Nunes de Souza. Avós que assumem a criação de netos. Pensando família, v. 17, n. 1, Porto Alegre, p. 87-98, jul. 2013.

MEIRELES, Fabrina da Silva; TEIXEIRA, Solange Maria. As diversas faces da família contemporânea: conceitos e novas configurações, Informe Econômico, Teresina, n. 31, p. 37, jun.,2014.

MORALES, Alejandro Tamez. Os predicados da parentalidade adotiva. In: SOLISPONTON, Letícia (Org.). Ser pai, ser mãe parentalidade: um desafio para o terceiro milênio. São Paulo: Casa do Psicólogo, 2004, p. 195-202.

NOGUEIRA-MARTINS, Maria Cezira Fantini; BÓRGUS, Cláudia Maria. Considerações sobre a metodologia qualitativa como recurso para o estudo das ações de humanização em saúde, Saúde e Sociedade, v.13, n.3, p.44-57, set./dez. 2004.

OLIVEIRA, Maíra Ribeiro de. Nascimento de filhos: rede social de apoio e envolvimento de pais e avós. Brasília: Universidade de Brasilia, 2007.

PIRES, Maria de Fátima Ferrão. Presença e papel dos avós: estudo de caso. Aveiro: Universidade de Aveiro. 2010.

PASSOS, Maria Consuêlo. Funções materna e paterna nas famílias homoparentais. In: FÉRES-CARNEIRO, Terezinha (Org.). Família e Casal: saúde trabalho e modos de vinculação. São Paulo: Casa do Psicólogo, 2007.

. Nem tudo que muda, muda tudo: um estudo sobre as funções da família. In: FÉRES-CARNEIRO, Terezinha (Org.). Família e Casal: efeitos da contemporaneidade. Rio de Janeiro: Editora da PUC, 2005, p. 11-23.

QUEIROZ, Luis Ricardo Silva. Pesquisa quantitativa e pesquisa qualitativa: Perspectivas para o campo da etnomusicologia. Claves, n. 2, nov. 2006, p. 87 - 98.

RIBEIRO, Alessandra Ventura Oliveira; VIANNA, Lucy Gomes; ÁRDENAS, Carmen Jansen de. Avosidade: Visões de avós e de seus netos no período da infância. Revista Brasileira de Geriatria Gerontologia, Rio de Janeiro, v. 13, n. 3, p. 461-474, 2010.

ROUDINESCO, E. A família em desordem. Rio de Janeiro: Jorge Zahar, 2003.

SILVA, Ana Mateus. A colaboração dos avos na educação dos netos. Interfaces Científicas - Educação, Aracaju, v. 1, p. 67-75, 2012.

SILVA, Janaina Teixeira.; COELHO, Raquel Santos.; CAMPOS, Carla Alves; OLIVEIRA, Edilene ; BORGES, Fernanda Correa ; OLIVEIRA, Kaline. Pais no exterior e netos sob total responsabilidade das avós: uma análise desta realidade. Encontro: Revista de Psicologia, v. $13, \mathrm{n}^{\circ} 18,2010$, p. 59-70. 
SOUZA, Ivone M. Candido Coelho de Souza. Papéis avoengos - uma sobreposição à parentalidade. In: SOUZA, Ivone M. Candido Coelho de Souza (Coord.). Parentalidade análise psicojuridica. Curitiba: Juruá, 2009. Pág. 165-182.

SOUZA, Liliana. Avós e netos: uma relação afectiva, uma relação de afectos. In: OLIVEIRA, João Muñoz de (Coord.). Povos e Culturas. Rio de Janeiro: CEP, 2006, p. 39-50.

ZORNIG, Silvia Maria Abu-jamra. Tornar-se pai, tornar-se mãe: o processo da construção da parentalidade. Tempo psicanalítico, Rio de Janeiro, v.42, n, 2, p.453-470, 2010.

Data de recebimento: $23 / 12 / 2014$

Data de aceite: 05/07/2017

\section{Sobre as autoras:}

Ana Luiza Xavier Scremin possui graduação em Psicologia pelo Centro Universitário Franciscano (2015). Tem experiência na área de Psicologia clínica com ênfase em crianças e adolescentes. Endereço Eletrônico: luiza.xavier@gmail.com

Cristiane Bottoli é psicóloga, mestre em psicologia, docente do curso de psicologia do Centro Universitário Franciscano. Endereço Eletrônico: cbottoli@ hotmail.com 